\title{
Hot Hydrogen Test Facility
}

\section{Space Technology and Applications International Forum -- STAIF-2007}

\author{
W. David Swank \\ Jon Carmack \\ James E. Werner \\ Robert J. Pink \\ DeLon C. Haggard \\ Ryan Johnson
}

February 2007

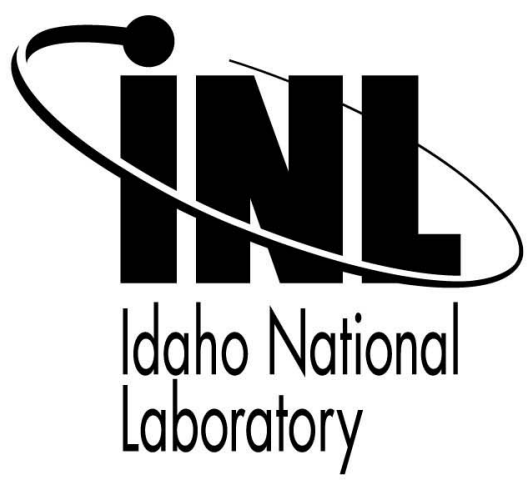

This is a preprint of a paper intended for publication in a journal or proceedings. Since changes may be made before publication, this preprint should not be cited or reproduced without permission of the author. This document was prepared as an account of work sponsored by an agency of the United States Government. Neither the United States Government nor any agency thereof, or any of their employees, makes any warranty, expressed or implied, or assumes any legal liability or responsibility for any third party's use, or the results of such use, of any information, apparatus, product or process disclosed in this report, or represents that its use by such third party would not infringe privately owned rights. The views expressed in this paper are not necessarily those of the United States Government or the sponsoring agency. 


\title{
Hot Hydrogen Test Facility
}

\author{
W. David Swank, Jon Carmack, James E. Werner, \\ Robert J. Pink, DeLon C. Haggard, Ryan Johnson
}

\author{
Idaho National Laboratory, PO Box 1625, Idaho Falls, ID 83415 \\ 208-526-1698,W.Swank@INL.gov
}

\begin{abstract}
The core in a nuclear thermal rocket will operate at high temperatures and in hydrogen. One of the important parameters in evaluating the performance of a nuclear thermal rocket is specific impulse, $\mathrm{I}_{\mathrm{SP}}$. This quantity is proportional to the square root of the propellant's absolute temperature and inversely proportional to square root of its molecular weight. Therefore, high temperature hydrogen is a favored propellant of nuclear thermal rocket designers. Previous work has shown that one of the life-limiting phenomena for thermal rocket nuclear cores is mass loss of fuel to flowing hydrogen at high temperatures. The hot hydrogen test facility located at the Idaho National Lab (INL) is designed to test suitability of different core materials in $2500^{\circ} \mathrm{C}$ hydrogen flowing at 1500 liters per minute. The facility is intended to test low activity uranium containing materials but is also suited for testing cladding and coating materials. In this first installment the facility is described. Automated data acquisition, flow and temperature control, vessel compatibility with various core geometries and overall capabilities are discussed.
\end{abstract}

Keywords: nuclear thermal rocket, hydrogen, testing.

PACS: 28.50.Ky.

\section{INTRODUCTION}

The specific impulse $\left(\mathrm{I}_{\mathrm{SP}}\right)$ of a rocket motor is defined as the ratio of thrust to propellant mass flow rate and is one of the criteria for evaluating rocket performance. It is a function of the thrust chamber temperature divided by the propellants molecular weight. Maximizing the thrust chamber temperature and minimizing the molecular weight of the propellant all contribute to a higher $I_{S P}$. Using a combination of high energy density nuclear fission with hydrogen propellant are obvious choices for extended space missions. There are numerous concepts for space nuclear power and propulsion. Both manned and unmanned long-term space missions plan to utilize compact nuclear reactors to provide electrical power and propulsion. However obvious the concept of nuclear thermal propulsion is, it is equally complex in materials technology. Reactor exit gas temperatures are limited to being less than the melting point of the materials used. Refractory metals, their compounds, and graphite are the best candidate materials. Tungsten melts at $3640 \mathrm{~K}$, graphite sublimes at $3825 \mathrm{~K}$ and $4 \mathrm{TaC}-\mathrm{ZrC}$ melts at $3950 \mathrm{~K}$. Nitrides, borides oxides, intermetallic compounds, silicides, and sulfides melt at substantially lower temperatures. Therefore the $\mathrm{I}_{\mathrm{SP}}$ for nuclear thermal rockets using hydrogen propellant is limited to $\sim 1200 \mathrm{sec}$. for moderate chamber pressures $(<3$ $\mathrm{MPa}$ ). This is nearly 3 times the performance of the best chemical propellants. With combustion temperatures limited to $\sim 3100 \mathrm{~K}$ and the higher molecular weight of the combustion products, chemical rocket $\mathrm{I}_{\mathrm{SP}}$ is only $\sim 450$ sec (Black and Gunn, 2001).

The general problem with space nuclear power is in protecting some of the functional elements from high temperature hydrogen. Core materials as well as materials for the collector and emitter of thermionic generators all need to be tested for their resistance and mechanical stability in hot flowing hydrogen. Recent work being carried out at the Marshall Space Flight Center on the Safe Affordable Fission Engine (SAFE) and Direct Drive Gas Cooled reactor has developed significant capability for non-nuclear testing of components and systems (Van Dyke 2004; Bragg-Sitton, 2006; Hrbud, et al. 2003; Godfroy, Kapernick, and Bragg-Sitton, 2004). The Rover/NERVA project of the 1970's provided extensive data and information for fuel element design (Koenig, 1986). Explained in some detail by Emrich (2006), the problem with fuel survivability is not associated with radiation damage but with a "mid band" corrosion phenomena where free carbon is lost through cracks in the coating material. Fuel element materials 
most often selected are tungsten or graphite in some combination with uranium. Some oxides, e.g. BeO, and intermetallic compounds e.g. $\mathrm{WBe}_{2}$, appear to also capable of meeting the requirements (Gontar, 2005). However, their properties in hot hydrogen environments are not well studied.

Presented here is a facility for understanding the thermal-hydralic behavior and stability of core, reflector, moderator and shielding materials. Not only will hot hydrogen flow testing with thermal cycling provide data on material survivability but data can be gathered for validation of heat transfer and fluid dynamic models. As progress is made towards nuclear power in space, the safety and operational readiness of any new reactor, in particular space reactors will require testing on critical components to prove their readiness and survivability.

\section{TEST APPARATUS}

The Hot Hydrogen Test Facility (HHTF) located at the Idaho National Lab (INL) is designed to test suitability of different core materials in $2500{ }^{\circ} \mathrm{C}$ hydrogen flowing at 1500 liters per minute. The facility is intended to test nonuranium containing materials and therefore is particularly suited for testing potential cladding and coating materials. Shown in Fig. 1, the vacuum/pressure vessel is a double walled water cooled cylinder consisting of three separate pieces: a main vessel chamber, a $20 \mathrm{~cm}$ instrumentation feed through spool piece, and upper hemispherical dome. This vessel is somewhat unique in that it is capable of operating from a high vacuum of 10-6 torr to a moderate pressure of $50 \mathrm{psig}$. The vessel has an overall length of $163 \mathrm{~cm}$ and an internal diameter of $45 \mathrm{~cm}$. The main chamber provides the primary test space and is designed with 3 access ports, $36 \mathrm{~cm}$ in diameter. Optical access is provided through two, $2.5 \mathrm{~cm}$ diameter quarts windows with mechanical shutters in each of the $41 \mathrm{~cm}$ flange blanks that cover the $36 \mathrm{~cm}$ ports. These shutters allow the windows to be shielded form direct shine of the hot zone when the window is not in use. High power feed troughs' are located directly above the $36 \mathrm{~cm}$ access ports for convenient connection to the experiment. A $20 \mathrm{~cm}$ long spool piece sits above the main chamber. Twelve $3.8 \mathrm{~cm}$ diameter access ports protrude radialy form this spool piece and provide instrumentation access above the heated experiment. Atop the $20 \mathrm{~cm}$ instrumentation access spool is a high dome top piece. This dome provides the needed space to perform tests on thermionic heat pipe modules or other extended length elements. It has only a single penetration which supports a multi-port tee for housing both a vacuum thermocouple gauge and a high vacuum nude ion gauge.

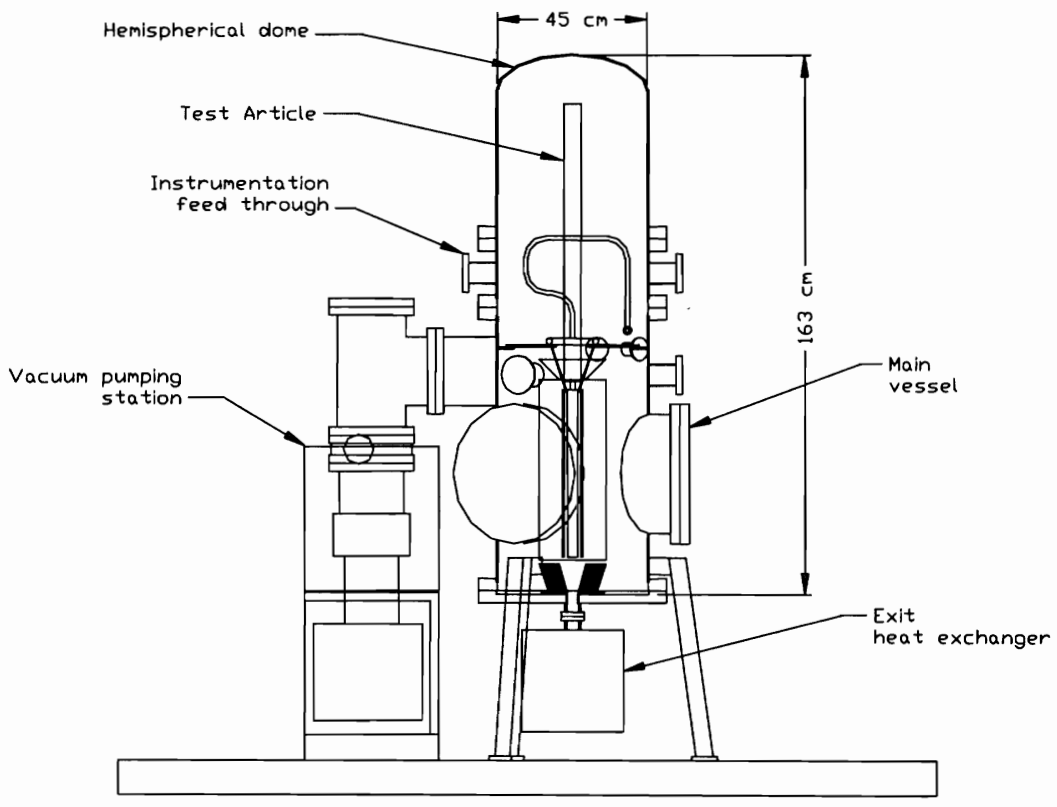

FIGURE 1. HHTF Test Vessel Layout.

Vessel evacuation is accomplished via a $20 \mathrm{~cm}$ port extending form the main chamber to a tee. Attached to the tee is a 1000 liter/sec turbo molecular pump backed by a double stage mechanical roughing pump. The turbo pump is operated through a controller that automatically handles startup and shutdown sequences and steady operation of the 
fore-pump, vent valve, and turbo pump. This system is capable of evacuating the vessel pressure to $10^{-6}$ torr prior to each experimental run.

Experiment heating is accomplished with a radio frequency (RF) induction heating power supply. This unit is capable of providing $50 \mathrm{~kW}$ of RF power between 150 and $400 \mathrm{kHz}$. Induction heating allows for a variety of experiment geometries and configurations. Custom heating coils are fabricated from $1 / 4$ inch diameter copper tube to match virtually any heating requirement. Other advantages afforded by induction heating include uniform and noncontact heating of conductive materials with accurate control of input power.

Fig. 2 is a schematic diagram of the gas flow and instrumentation. Either helium or hydrogen gas can be fed from the storage bottles to the test article via $1.2 \mathrm{~cm} 304$ stainless steel tubing. Helium is used during initial warm-up of the system and purging once hydrogen testing is complete. During the test, hydrogen passes from the pressure regulator, through the particulate filter where the flow is split with one leg feeding a cold hydrogen line, the "cold leg", that connects directly to the vessel and the other leg feeding the inlet gas pre-heater, the "hot leg". An absolute pressure transducer measures the inlet line pressure prior to the flow split and relays the signal to the data acquisition and control (DAC) system. Flow in the hot leg passes through a mass flow controller. This mass flow controller is interfaced to the DAC and can be set remotely from 1 to 1500 standard liters/minute.

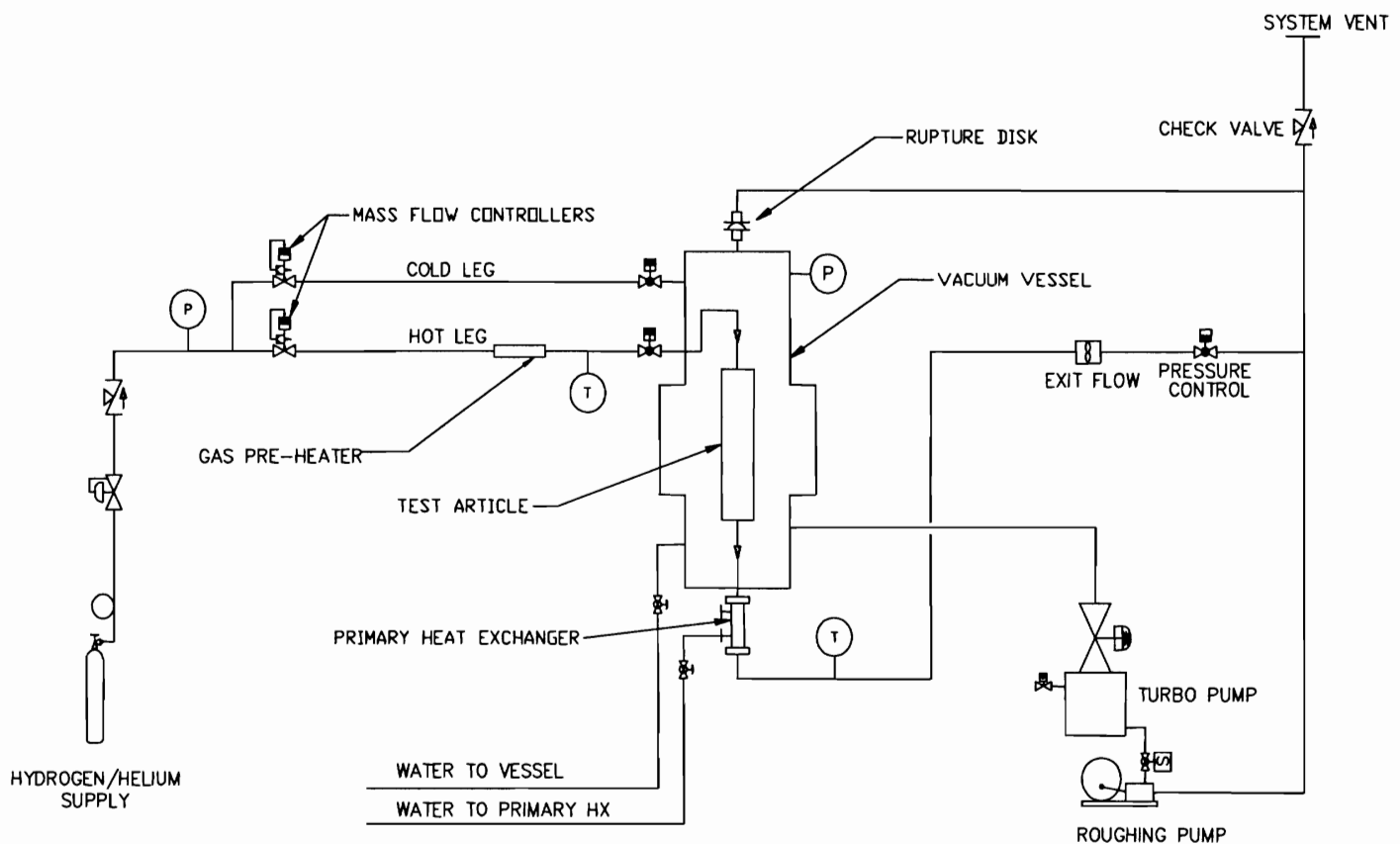

FIGURE 2. Process Diagram for Hot Hydrogen Test Facility.

Downstream of the mass flow control meter, the gas passes through a remotely operated flow isolation valve before entering the gas pre-heater. This pre-heater is a $30 \mathrm{~kW}, 480 \mathrm{~V} 3$ phase SCR controlled resistance heater that uses 6 inline nichrome heat coils arranged in a hexagonal array to preheat the hydrogen gas stream to a maximum temperature of $800 \mathrm{~K}$. The pre-heater is feedback controlled on exit gas temperature using a type-K thermocouple and a Proportional-Integral-Derivative (PID) controller in the DAC system. The preheated gas passes through a second flow isolation valve before entering the main vessel via a high temperature, insulated feed-through. The gas temperature is again monitored using a type- $\mathrm{K}$ thermocouple just prior to entering the vessel.

A bypass flow loop is provided downstream of the pre-heater that allows the preheated gas to be cooled by a secondary heat exchanger and then exhausted through the vent line without entering the vessel and passing trough the primary heat exchanger. This provides two key operation options. First, the test gas can be brought to its desired temperature independent of the vessel and the test article. Once the gas is preheated to its desired 
temperature, the flow can be introduced in the vessel, thus providing the flexibility to expose the test article to either cold flow during startup or fully pre-heated gas. A second benefit is that once gas testing is complete, the vessel can be bypassed and returned to vacuum while allowing the gas flow system to be cooled independently.

Flow in the cold leg passes an overpressure relief valve, through a flow isolation valve, through another 0 to 1500 slpm flow controller and then into the main vessel. This cold leg flow allows filling of the vessel with cold hydrogen prior to testing. It also provides the option of flowing a secondary stream of cold hydrogen into the vessel during testing. If needed, this cold leg flow will help to maintain a cooler environment in the vessel outside of the hot zone as certain instrumentation and diagnostic equipment have low operating temperature limits.

Located in the bottom of the vessel is the $5 \mathrm{~cm}$ gas exit. Depending on different testing requirements and conditions, gas exiting the experiment hot zone may be up to $2500 \mathrm{~K}$ in which case it is necessary to dilute the hot gas stream with gas from the cold leg and provide initial cooling with a finned copper chill block in the bottom of the vessel. It is also possible to use a tungsten flow tube that directs the hot gas immediately onto the inlet manifold of the high temperature heat exchanger. The primary heat exchanger can accept gas temperatures up to $2300 \mathrm{~K}$ at a flow rate of 2 grams/sec. The heat exchanger consists of a water cooled hydrogen inlet manifold and main body. The inlet manifold was designed to serve two purposes. First, it directs the hydrogen flow from the hot zone through the vessel penetration and into the main heat exchanger body. And second, it is capable of providing mechanical support for the test article. It is a helically coiled shell and tube unit with the gas on the tube side. Water flow around the tubes provides the necessary heat removal. It is designed to discharge the gas at or near room temperature for subsequent handling and analysis.

After the gas is cooled it exits the heat exchanger and passes through a flow meter whose reading is compared to the sum of the two inlet gas flow controllers to detect any gross leakage of process gas. Finally the exit gas passes through a flow control valve that is tied to the system pressure set point using the vessel pressure measurement and a PID controller in the DAC software. Operating pressure for the vessel is variable depending upon the desired test conditions but is normally controlled at 50 psig.

The Hot Hydrogen Test Facility has the capability to fully monitor and record process temperatures, pressures, flow rates, of the gas, water and test article subsystems. Data acquisition and control consists of a computer, National Instruments multifunction data acquisition card, signal conditioning instrumentation and sensors. The computer is a $3 \mathrm{GHz}$ PC with 1 Gbyte of ram and houses the data acquisition card running through the PCI bus. This device is capable of scanning 32,0 to $10 \mathrm{~V}$, analog input channels at $1 \mathrm{MS} / \mathrm{sec}$ with NIST traceable calibration. It has 4,16 bit analog outputs that are used for control of proportional valves and heaters. In particular the outlet gas temperature of the hot leg gas supply is controlled by a PID feed back loop to the heater power. PID control is also utilized for the vessel outlet pressure by controlling a proportional flow valve at the exit of the gas system. Process sensor signals are conditioned through instrumentation readouts that have either 0 to 10 volt or 4 to $20 \mathrm{~mA}$ output for input to the data acquisition card. LabView software is used to control this automated test and measurement system. Its graphical programming interface provides flexible, scalable and maintainable software for the system. As requirements change for various test articles the data acquisition and control software can be efficiently modified to meet those needs.

\section{DIAGNOSTIC CAPABILITIES}

The HHTF has been designed to accept a wide variety of test articles and their specific requirements. Diagnostic capability beyond simple inlet/outlet flow condition measurements is critical for a complete scientific understanding of test results. To this end, the INL team is capable of performing optical temperature and water cooled gas sampling stagnation probe measurements with complete interpretation of the complex results. Two such systems are described below.

\section{Enthalpy Probe/Mass Spectrometer System}

An enthalpy probe is a water jacketed gas sampling and stagnation pressure probe from which the enthalpy, temperature, and velocity of a hot flowing gas can be derived once the composition is known (Swank, Fincke, and Haggard 1993). A schematic diagram is shown in Fig. 3. Gas enthalpy is determined using a calorimetric method that depends heavily on a tare or difference measurement. Observations of the coolant temperature rise and flow rate are 
made while no gas flows through the inner diameter of the probe. Gas is then allowed to flow and the same coolant measurements are repeated, together with measurements of the gas mass flow rate and gas temperature at the probe exit. The rate of heat removal from the gas sample is thus given by the difference between the measured delta of cooling water inlet and outlet temperatures:

$$
\dot{m}_{g}\left(h_{l g}-h_{2 g}\right)=\dot{m}_{c w} C_{p}\left\lfloor\left(\Delta T_{c w}\right)_{\text {gas flow }}-\left(\Delta T_{c w}\right)_{\text {no gas flow }}\right\rfloor .
$$

Provided the gas sample flow rate, $\mathrm{m}_{\mathrm{g}}$ and the gas enthalpy, $\mathrm{h}_{2 \mathrm{~g}}$ at the probe exit are known, the unknown gas enthalpy $\mathrm{h}_{\mathrm{lg}}$ at the probe tip can be calculated. The exit gas enthalpy is determined from the measured temperature at atmospheric pressure and the gas sample flow rate is measured via a sonic orifice.

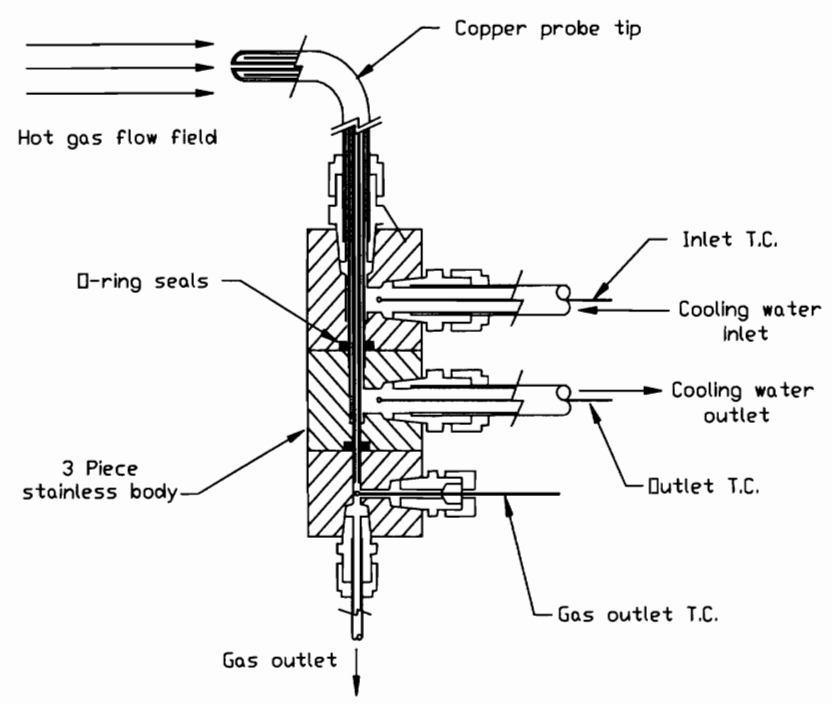

FIGURE 3. Enthalpy Probe Cross Section.

While the probe is in the "no gas flow" mode of the measurement it behaves like a water-cooled pitot tube and the stagnation pressure is determined at the probe tip. Then for low Mach numbers the free stream velocity, V, of the hot gas may be calculated from:

$$
V=\left[\frac{2}{\rho}\left(P_{\text {stag }}-P_{\text {atm }}\right)\right]^{\frac{1}{2}}
$$

Thermodynamic properties such as density and enthalpy, are determined from a Gibbs free energy minimization calculation (Gordon and McBride, 1976). For input to this calculation the gas composition is measured. This is accomplished by integrating the enthalpy probe with a mass spectrometer. During the gas flow phase of the measurement, a gas sample is bled off to a quadrapole mass spectrometer or residual gas analyzer (RGA). The RGA (Leybold-Heraeus Inficon Quadrex 100) is set up in a differentially pumped vacuum system.

The probe itself is fabricated from three concentric tubes. The outer tube is copper and has an outside diameter of 4.8 $\mathrm{mm}$. The inner most tube is also copper and has an inside diameter of $0.78 \mathrm{~mm}$. Copper was chosen because of its high thermal conductivity and formability. The middle tube is stainless steel and is not a pressure or heat transfer boundary, but guides the cooling water to and from the tip of the probe.

While the construction of the probe is relatively simple, the calibration of the entire enthalpy probe system is complex. The Residual Gas Analyzer is the most difficult and critical portion of the system to calibrate. Calibration is 
accomplished using known mixtures of the gases being investigated. The limitations of the mass spectrometer and the largest source of error resides in the resolution of its 8 bit digitizer. This resolution error is minimized by optimizing the operating voltage of the electron multiplier and by adjusting the individual mass channel electronic gains until a reasonable sensitivity is achieved. Optimizing the gain in this way results in an uncertainty of $10 \%$ in the air fraction measurement, when the air fraction is in the neighborhood of 0.2 . Using standard techniques (Kline and MClintock 1953 ) the estimated $2 \sigma$ (standard deviation) uncertainty in measured enthalpy is $5.3 \%$ with the major source of error being the determination of the gas mass flow rate through the probe. This error stems primarily from the inaccuracy of the thermocouple temperature measurement up stream of the sonic orifice. The combination of a $10 \%$ uncertainty in properties and a $5.3 \%$ uncertainty in the measured enthalpy result in an acceptable $2 \sigma$ uncertainty of $4.9 \%$ in the temperature. The gas mixture density is the major source of error in the gas velocity uncertainty of $6.3 \%$.

\section{Two Color Pyrometer}

For many experiments only non-intrusive optical temperature measurement techniques are applicable. These techniques deduce the temperature of an object by measuring the intensity of radiation emitted by the object in one or more spectral (wavelength or color) bands. A two-color pyrometer measures the temperature by calculating the ratio of the emitted radiation in two different spectral bands. By using the ratio, the measurement is less sensitive to the emissivity of the material being observed and the absolute radiation falling on the detector, than is the case for pyrometers using a single wavelength band. The technique is however susceptible to errors caused by variations of emissivity with wavelength and special precautions must be observed to ensure that adequate signal strength is available to obtain an accurate measurement. In order to avoid these difficulties and to facilitate the use of a twocolor optical pyrometry for the measurement of test article temperature, a number of modifications and improvements have been engineered into the INL two color pyrometer (Swank, Fincke, Haggard, 1995).

The basic premise behind all radiation thermometry is Plank's Law, which describes the emissive power of a radiating body as a function of wavelength, emissivity and temperature. Dual-wavelength (ratio or two color) pyrometry involves the measurement of the spectral energy in two different wavelength bands. Using Planck's law the ratio of radiant energy, $R$, in two different wavelength bands, $\lambda_{1}$ and $\lambda_{2}$, is given by:

$$
R=\frac{\varepsilon_{\lambda_{1}}}{\varepsilon_{\lambda_{2}}}\left(\frac{\lambda_{1}}{\lambda_{2}}\right)^{-5} \exp \left[-\frac{C_{2}}{T}\left(\frac{1}{\lambda_{1}}-\frac{1}{\lambda_{2}}\right)\right]
$$

This two color pyrometer consists of three main components, the electronics, the optical measurement head, and the fiber cable which connects the two. The sensor head is compact and contains only passive optical components. The objective lens is interchangeable to provide a variety of standoff distances. The objective lens forms a measurement volume that is pencil shaped, $5 \mathrm{~mm}$ in diameter and approximately $50 \mathrm{~mm}$ long. The temperature is then determined form the light gathered over this $5 \mathrm{~mm}$ diameter spot. The sensor head is coupled to the electronics via a fiber optic cable. Fiber optic coupling allows maximum flexibility of deployment while providing isolation of the electronics from the hot experiment. The fiber optic delivers light to the solid state detectors housed inside the electronics. Standard band centers for the two colors are $\lambda_{\mathrm{CH} 1}=0.95 \mu \mathrm{m}$ and $\lambda_{\mathrm{CH} 2}=1.35 \mu \mathrm{m}$. Frequency response is limited to $10 \mathrm{~Hz}$.

Alignment is facilitated by the ability to project a visible spot of light through the optical fiber and the imaging optics in the optical head. The visible projected spot coincides with the measurement volume extent as well as its location. Along with a digital temperature display the device provides both single color and two-color ratio analog outputs which are suitable for input to the control and data acquisition system.

Over the range of temperatures for which the pyrometer is applied (1000 to $4000 \mathrm{~K})$ and because of the way in which the spectral bandwidths and band centers are chosen, the temperature as a function of the ratio of radiant energy can be approximated by a linear function of the measured voltage ratio, $\mathrm{V}_{\mathrm{CH} 1} / \mathrm{V}_{\mathrm{CH} 2}$. The expression for the observed ratio temperature, $\mathrm{T}$, is given by:

$$
T=A+B\left(\frac{V_{c h 1}}{V_{c h 2}}\right) .
$$


Using this approximation the pyrometer is calibrated against a tungsten ribbon standard. The square of the residuals for this linear calibration is $>0.995$. This end to end calibration takes into account responsivities, area, and amplifier differences in the detectors and when calibrated on a tungsten lamp, includes the spectral emissivity variation of tungsten. For materials with a spectral emissivity ratio similar to tungsten, 1.29 (De Vos 1954) the uncertainty in the absolute temperature read by the pyrometer is on the order of $\pm 5 \%$.

For applications where the absolute measurement of temperature is desirable, emissivity correction factors should be considered. The problem is basically one of how to infer the true temperature from the radiant energy sensed by the pyrometer. If the relationship between emissivity and wavelength is known it is possible to estimate a correction from the tungsten calibration. The difference between the temperature read by the pyrometer, $T_{w}$, and the true temperature, $\mathrm{T}_{\mathrm{x}}$ of a material who's spectral emissivity ratio differs from that of tungsten, is found from setting the ratio of emissive powers for material $x$ equal to that of tungsten, $w$, to arrive at:

$$
\frac{1}{T_{x}}=\frac{1}{T_{w}}+\frac{\ln \left(\frac{\varepsilon_{\lambda_{1}}}{\varepsilon_{\lambda_{2}}}\right)_{w}\left(\frac{\varepsilon_{\lambda_{2}}}{\varepsilon_{\lambda_{1}}}\right)_{x}}{C_{2}\left(\frac{1}{\lambda_{1}}-\frac{1}{\lambda_{2}}\right)} .
$$

Shown in Fig. 4 is the true temperature as a function of the temperature read by the pyrometer as described by equation 5 for different spectral emissivity ratios. Many metallic materials such as nickel, stainless steel, and inconel have spectral emissivity ratios between 1.20 and that of tungsten, 1.29 (Touloukian, and Dewitt, 1970). For a pyrometer reading of $2000 \mathrm{~K}$, the true temperature, $\mathrm{T}_{\mathrm{x}}$, for a material with an emissivity of 1.20 would be $2066 \mathrm{~K}$. Many metal oxides and ceramics behave more like gray bodies, i.e. their emissivity ratio is unity (Touloukian, and Dewitt, 1972). In this case the actual temperature, $T_{x}$, of the particles is $2256 \mathrm{~K}$ while the pyrometer reads $2000 \mathrm{~K}$. This gray body correction represents the worst case. Although the difference between the gray body temperature and the tungsten calibration is significant the linearity of this correction over the useful temperature range makes it relatively simple to program the temperature display to read the correct temperature.

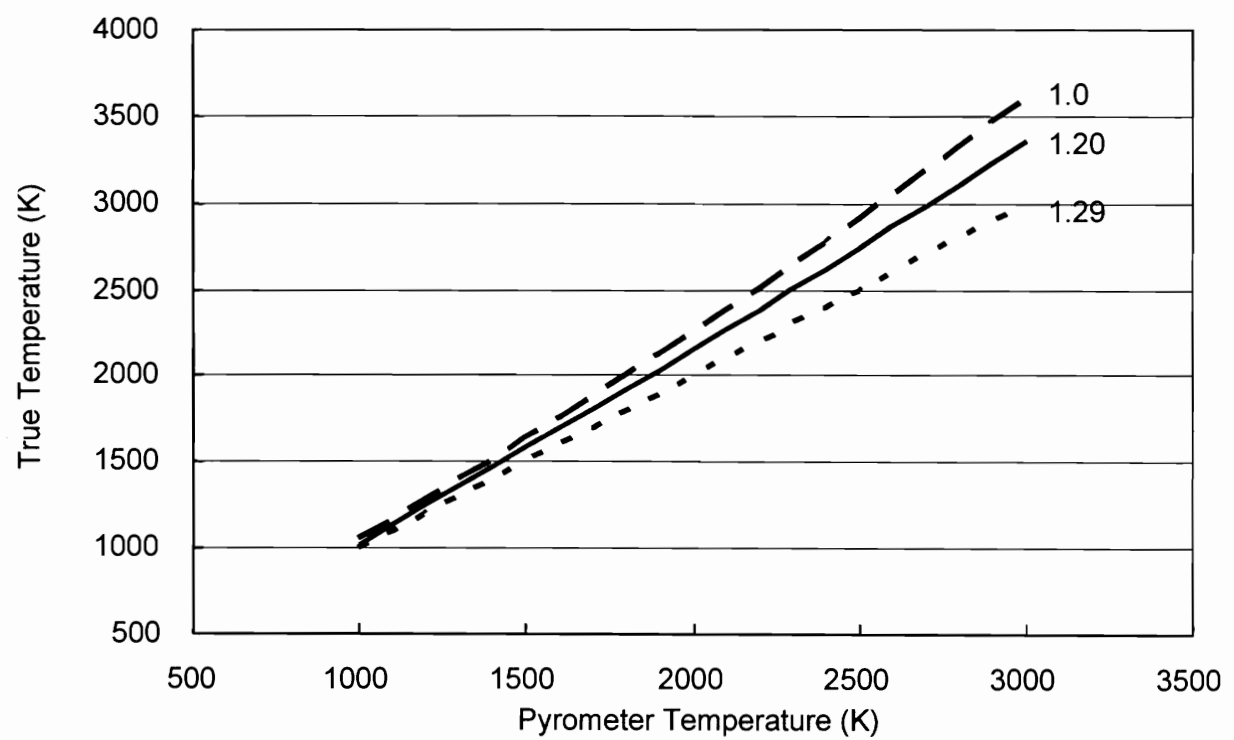

FIGURE 4. Pyrometer Emissivity Correction for Ratios of 1.0, 1.2, and 1.29.

The procedure described above should be considered only a first order correction. The development of more precise corrections is possible; however it depends heavily on the materials, temperature ranges, formation of oxide layers 
or other chemical reactions, etc. Unfortunately it is not possible to provide a simple general correction for all situations which may be encountered.

\section{SUMMARY}

An experimental facility for testing nuclear system components and materials in hot, flowing hydrogen is under development at the Idaho National Laboratory (INL). This facility simulates anticipated in-core thermal and fluid conditions for various proposed space nuclear power and propulsion systems. The test bed will accommodate a heated test article with a length of $\sim 50 \mathrm{~cm}$ and a diameter of $\sim 10 \mathrm{~cm}$. A number of different experiments may be performed with very little modification to the overall system. Vacuum, helium, and hydrogen flow experiments can be performed in the same vessel. Transients arising from starting a hydrogen flow past a core component operating at high temperature can also be studied.

Future tests of components and materials with hydrogen flow rates and temperatures up to $2 \mathrm{~g} / \mathrm{s}$ and $2500 \mathrm{~K}$ are planned. Tests include heat transfer characteristics, effect of gas flow on core components, thermal hydraulic performance, and high temperature hydrogen gas material compatibility. With the addition of an off gas system, experiments could include irradiated core components, fission product research, and uranium composite propellant compatibility.

\section{NOMENCLATURE}

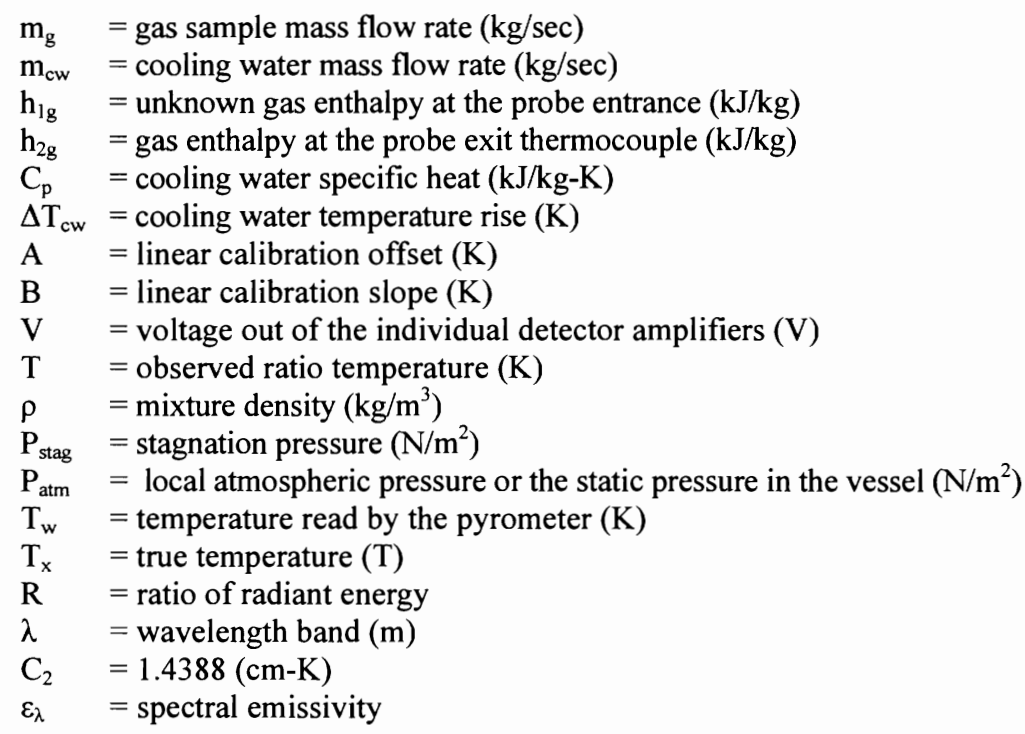

\section{ACKNOWLEDGMENTS}

This work was supported by the U.S. Department of Energy, Office of Nuclear Energy, under DOE Idaho Operations Office Contract No. DE-ACO7-05ID14517.

\section{REFERENCES}

Black, D.L., Gunn S.V., Encyclopedia of Physical Science and Technology, $3^{\mathrm{RD}}$ Edition, edited by Robert. A. Meyers, Academic Press, Tarzana CA, 2001, pp. 555-575.

Bragg-Sitton, S. M., Morton T. J., "Dynamic Response Testing in an Electrically Heated Reactor Test Facility," in proceedings of Space Technologies and Applications International Form (STAIF-2006), edited by M.S. El-Genk, AIP Conference proceedings 813, Melville New York, 2006, pp. 396-407.

De Vos, J.C., "A new determination of the emisivity of tungsten ribbon," Physica, XX, 690-714, (1954).

Emrich, W.J., "Non Nuclear NTR Environmental Simulator," in proceedings of Space Technology and Applications International Form (STAIF-2006), edited by M.S. El-Genk, AIP Conference Proceedings 813, Melville New York, 2006, pp. 531-536. 
Gordon, S. and McBride, B., Computer Program for Calculation of Complex Chemical Equilibrium Compositions, Rocket Performance, Incident and Reflected Shocks, and Chapman-Jouguet Detonations, NASA SP-273, NASA Lewis Research Center, Cleveland, OH, 1976.

Godfroy T.J., Kapernick R. J., Bragg-Sitton S.M., "Thermally Simulated 32kW Direct-Drive Gas-Cooled Reactor: Design, Assembly, and Test," in the proceedings of Space Technology and Applications International Form (STAIF-2004), edited by M.S. El-Genk, AIP Conference Proceedings 699, Melville New York, 2004, pp. 757-763.

Hrbud, I., Goodfellow K., Van-Dyke M., et al., "Non-Nuclear NEP System Testing," in the proceedings of Space Technology and Applications International Form (STAIF-2003), edited by M.S. El-Genk, AIP Conference Proceedings 654, Melville New York, 2003, pp. 533-539.

Kline, S.J., and McClintock F.A., "Describing Uncertainties in Single-sample Experiments," Mechanical Engineering, 75, 3-9, (1953).

Koenig, D., Experience Gained from the Space Nuclear Rocket Program (Rover), LA-10062-H, Los Alamos National Laboratory, Los Alamos, NM, 1986.

Swank, W.D., Fincke J.R., and Haggard, D.C., "Modular enthalpy probe and gas analyzer for thermal plasma measurements," Review of Scientific Instruments, 64 (1), 56-62, (1993).

Swank, W.D., Fincke, J.R., and Haggard, D.C., "A Particle Temperature Sensor for Monitoring and Control of the Thermal Spray Process," in proceedings of Thermal Spray Science \& Technology, edited by C.C. Berndt and S. Sampath, ASM International, Materials Park, OH, 1995, pp. 111-116.

Touloukian, Y. S. and D. P. Dewitt, Thermal Radiative Properties Metallic Elements and Alloys, 7, IFI/Plenum, NewYorkWashington, 1970.

Touloukian, Y.S. and D. P. Dewitt, Thermal Radiative Properties Nonmetallic Solids, 8, IFI/Plenum, NewYork-Washington, 1972.

Van Dyke, M., "Early Flight Fission Test Facilities (EFF-TF) To Support Near-Term Space Fission Systems," in proceedings of Space Technology and Applications International Form (STAIF-2004), edited by M.S. El-Genk, AIP Conference Proceedings 699, Melville New York, 2004, pp. 713-719. 